\title{
Estimation of luliconazole in formulation and biofluid
}

\begin{abstract}
A new, simple, rapid and economic a High Performance Thin Layer Chromatography (HPTLC) method was developed and validated for quantitative determination of Luliconazole in pharmaceutical dosage form. The $\mathrm{R}_{\mathrm{f}}$ value of the drug was $0.62 \pm 0.05$ using Toluene: Methanol: Ethyl Acetate $(6: 2.5: 0.5 \mathrm{v} / \mathrm{v} / \mathrm{v})$ as the mobile phase at $300 \mathrm{~nm}$. Linearity was obtained within a concentration range of $100-600 \mathrm{ng} / \mathrm{band}$ with regression coefficient 0.983 . The accuracy of the proposed method for analyzing the API in terms of percentage recovery was 99.91 with percentage RSD $0.47 \%$, both of which were within the specified limits. LOD and LOQ were $27 \mathrm{ng} / \mathrm{band}$ and $83 \mathrm{ng} / \mathrm{band}$, respectively. The recovery after application to biological fluid was 100.36 with percentage RSD $0.69 \%$ proving its applicability to biological analysis. Mass spectrometric characterization of the samples resulted in a spectrum showing molecular ion peak at $355.1 \mathrm{~m} / \mathrm{z}$, resulted in direct confirmation in identifying the drug. The experimental data was statistically analysed by one way ANOVA (F-test) and student's t test which proves that, the developed chromatographic method is precise and accurate and can be used for routine analysis of Luliconazole. This HPTLC method seems to be convenient as well as less time consuming and thus illustrating its wide applicability for the estimation of Luliconazole in bulk drug, cream formulation and biological fluid.
\end{abstract}

Keywords: HPTLC, luliconazole, biological fluid
Volume 6 Issue 5 - 2017

\author{
Santosh R Tambe, Sawant SD, Anuja P \\ Bhosale \\ Department of Pharmaceutical Chemistry, Savitribai Phule Pune \\ University, India
}

\author{
Correspondence: Santosh R Tambe, Department of \\ Pharmaceutical Chemistry, MGV?s Pharmacy College, \\ Panchavati, Mumbai-Agra Road, Nashik- 422003, Maharashtra, \\ India, Tel 94035।5755, Fax 0253- 25। I931, \\ Email santoshsrt.mgv@gmail.com
}

Received: October 28, 2017 | Published: December 12, 2017
Abbreviations: HPTLC, high performance thin layer chromatography; LLCZ, luliconazole; ANOVA, analysis of variance

\section{Introduction}

Luliconazole is a novel topical antifungal imidazole with broadspectrum and potent antifungal activity used in treatment of superficial mycoses. Superficial mycoses are not fatal, but they constitute a serious problem for patients'quality of life in view of the considerable discomfort and/or cosmetic deformity they cause. These diseases are found worldwide and affect 20 to $25 \%$ of the world's population. Dermatophytosis is the most common infection among the superficial mycoses. ${ }^{2-8}$ Luliconazole is a novel antifungal drug launched in India by Ranbaxy Laboratories Ltd. The compound was originally screened from active compounds related to lanoconazole, a potent antidermatophytic drug. Currently, a $1 \%$ cream and a $1 \%$ solution of LLCZ are available for the treatment of superficial mycoses such as dermatophytosis, candidiasis, and pityriasis versicolor. Topical LLCZ has been introduced in India (approved in 2010). The compound was originally screened from active compounds related to lanoconazole, a potent antidermatophytic drug. The in vitro antifungal activity of LLCZ against Trichophyton spp. was found to be the highest among existing topical antifungal drugs. ${ }^{9-12}$ Literature survey revealed that there are very limited number of analytical methods available for estimation of Luliconazole ,such as a validated stability- indicating LC method for Luliconazole in bulk and cream formulation, ${ }^{13}$ the analytical methods developed for Luliconazole includes LC-MS/MS method for the determination of the Luliconazole in human toenails, ${ }^{14}$ RP HPLC Method for Assay and related Substances of Luliconazole in Topical Dosage form ${ }^{15}$ UV Spectrophotometric Method For The Estimation of Luliconazole In Marketed Formulation (Lotion). ${ }^{16}$ No HPTLC method was reported for quantitative estimation of Luliconazole. Thus, a simple and rapid high performance thin layer chromatography method has been developed and validated for Luliconazole.

\section{Materials and methods}

\section{Chemicals, reagents and Materials}

A reference standard, Luliconazole chemically, 4 - (2,4-dichlorophenyl)-1,3-dithiolan-2-ylidene-1imidazolylacetonitrile (Figure 1), was kindly supplied by Ranbaxy Laboratories Ltd. (Gurgaon, Haryana, India). The cream formulation, Lulifin $^{\mathrm{TM}}$ (Ranbaxy Laboratories Ltd., Gurgaon, Haryana, India) composed of $10 \mathrm{mg}$ of Luliconazole in each gram, was purchased in the market. Silica Gel $60 \mathrm{~F}_{254}$ TLC plates $(10 \mathrm{X} 10 \mathrm{~cm}$, layer thickness $0.2 \mathrm{~mm}$, E. Merck, Darmstadt, Germany) were used as stationary phase. Methanol, Ethyl acetate and Toluene (AR grade, Fisher Scientific, India) were used for mobile phase preparation.

\section{HPTLC method and chromatographic conditions}

Sample application: The standard and formulation samples of Luliconazole were spotted on Precoated TLC plates in the form of narrow bands of lengths $6 \mathrm{~mm}$, with $8.0 \mathrm{~mm}$ from the bottom and left margin $15 \mathrm{~mm}$ and with $10 \mathrm{~mm}$ distance between two bands. Samples were applied under continuous drying stream of nitrogen gas at constant application rate.

\section{Mobile phase and migration}

Plates were developed using mobile phase consisting of Toluene: Methanol: Ethyl Acetate $(6: 2.5: 0.5 \mathrm{v} / \mathrm{v} / \mathrm{v})$. Linear ascending development was carried out in $20 \mathrm{~cm} \times 20 \mathrm{~cm}$ twin trough glass chamber equilibrated with mobile phase. The optimized chamber saturation time for mobile phase was $20 \mathrm{~min}$ at $25 \pm 2{ }^{\circ} \mathrm{C}$. Ten milliliters of the mobile phase $(5 \mathrm{~mL}$ in trough containing the plate and $5 \mathrm{~mL}$ in other trough) was used for each development and allowed to migrate a distance of $70 \mathrm{~mm}$, which required $10 \mathrm{~min}$. After development, the TLC plates were dried completely. 


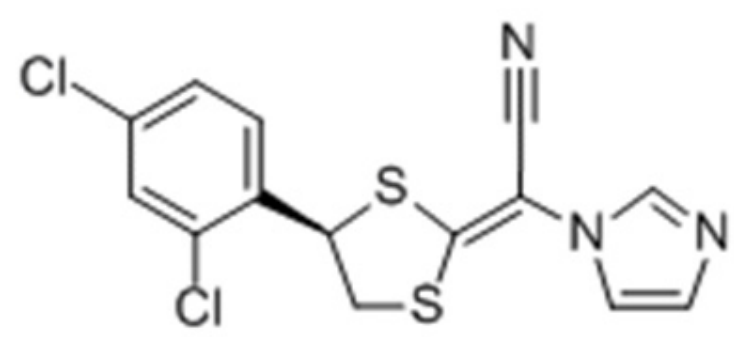

Figure I Structure of Luliconazole.

\section{Densitometric analysis and quantitation procedure}

Densitometric scanning was performed on Camag TLC scanner III in absorbance mode and operated by winCATS planar chromatography version 1.4.2.8121. The source of radiation utilized was deuterium lamp. The spots were analyzed at a wavelength of $300 \mathrm{~nm}$.Concentrations of compound chromatographed was evaluated as peak areas against concentrations using linear regression equation.

\section{Preparation of luliconazole standard stock solution}

Stock solution was prepared by weighing Luliconazole (10mg). Weighed powder was accurately transferred to a volumetric flask of $10 \mathrm{~mL}$ and dissolved in and diluted to the mark with methanol to obtain a standard stock solution of Luliconazole $(1 \mathrm{mg} / \mathrm{mL})$.

Method validation: Validation of the developed HPTLC method in bulk, cream was carried out as per the ICH Q2 (R1) guideline ${ }^{17}$ and method was also applied to biological fluid. The experimental data was statistically analysed by one way ANOVA for intraday and interday precision and $\mathrm{F}$ values were calculated at each low, medium and high conc. level. Student's t test was applied to accuracy data and $\mathrm{t}$ value was calculated.

Specificity: The specificity of the developed method was established analyzing the sample solutions containing Luliconazole from marketed formulations in relation to interferences from formulation ingredients and biological fluid. The spot for Luliconazole in the sample was confirmed by comparing $\mathrm{R}_{\mathrm{f}}$ values of the spot with that of the standard.

Sensitivity: Sensitivity of the method was determined with respect to limit of detection (LOD) and limit of quantitation (LOQ) by using the Standard Deviation of the Response and the Slope .The slope (S) was estimated from the calibration curve of the analyte and the standard deviation of y-intercepts of regression lines was used as the standard deviation $(\sigma)$ based on Calibration Curve method. Six sets of Series of concentrations of drug solutions (100-600ng/spot) were applied on plate and analyzed to determine LOD and LOQ. LOD was calculated as 3times the noise level, and LOQ was calculated as 10times the noise level.

Linearity and calibration curve: Linearity of the method was evaluated by constructing calibration curves at six concentration levels. Calibration curves were plotted over a concentration range of $100-600 \mathrm{ng} / \mathrm{spot}$. Aliquots of standard working solution of Luliconazole were applied to the plate $(1,2,3,4,5$, and $6 \mu \mathrm{L} /$ spot $)$. The calibration curves were developed by plotting peak area versus concentrations $(n=6)$ with the help of the winCATS software.

Accuracy: Accuracy of the method was evaluated by carrying the recovery study at three levels. Recovery experiments were performed by adding three different amounts of standard drug, that is, $80 \%$,
$100 \%$, and $120 \%$ of the drug, to the preanalyzed formulation solution. Data was analyzed and $t$ value was calculated by student's t test.

Precision: Precision was evaluated in terms of Intraday and Interday precisions. Intraday precision was determined by analyzing sample solutions of Luliconazole from at three levels covering low, medium, and higher concentrations of calibration curve for three times on the same day. Interday precision was determined by analyzing sample solutions of Luliconazole at three levels covering low, medium, and higher concentrations. Mean, relative standard deviation (RSD) and F values of peak area were obtained.

Robustness: By introducing small changes in mobile phase composition, chamber saturation time, Change in slit width, Change in Wavelength, Change in scan speed Robustness of the method was determined in $(n=3)$ at a concentration level of $300 \mathrm{ng} / \mathrm{spot}$ and \%RSD of peak area was calculated.

\section{Analysis of cream formulation}

An appropriate portion of $0.1 \mathrm{~g}$ of Lulifin ${ }^{\mathrm{TM}}$ was weighed and transferred into a $10 \mathrm{~mL}$ volumetric flask using weight by transfer method. Further, $5 \mathrm{~mL}$ of methanol was added and was shaken, till the cream base gets dissolved. Finally the volume was adjusted to the mark with methanol to get final concentration of $1 \mathrm{mg} / \mathrm{ml}$. As such three samples were prepared .The mixture were filtered immediately with Whatman filter paper no. 41 and subjected to chromatographic analysis. The drug peak area was referred to the regression equation to get the sample concentration and \% nominal label claimed.

\section{Application of the proposed method for estimation of luliconazole in biological fluid}

$0.25 \mathrm{ml}$ of biological fluid was deproteinated by acetonitrile and spiked with working solutions to produce desired concentrations of luliconazole. The precipitated mixture was shaken for 20 sec on a Vortex Shaker at maximum speed followed by centrifugation at 10,000 rpm for $1 \mathrm{~min}$ at room temperature. By using the same procedure the sample was prepared and analyzed in triplicate. $\mu \mathrm{L}$ volume of sample were applied on HPTLC plate to produce $300 \mathrm{ng} / \mathrm{ml}$ of sample under above conditions. The spiked specimens were then processed using the fore mentioned procedures and analysed. Specificity study showed that the components of biological matrix did not interfere with the analyte, thereby confirming the specificity of the proposed extraction procedure (Figure 2). The recovery of Luliconazole was calculated by comparison of the peak area of $300 \mathrm{ng} / \mathrm{ml}$ prepared in biological fluid (extracted) with unextracted Luliconazole.

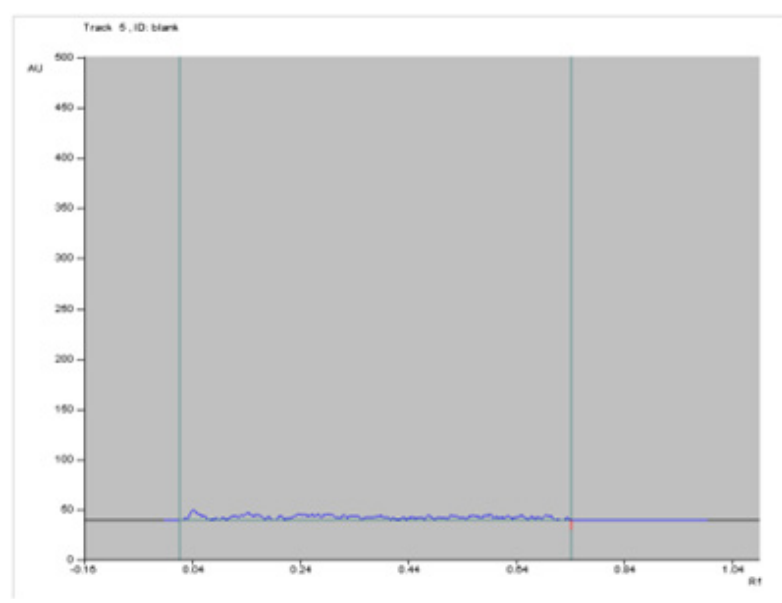

Figure 2 Drug free biological matrix (blank sample). 
Characterization by mass spectrometry: The triple quadrupole system was an API 4000 Q TRAP (ABSCIEX, CA, USA) LC-MS/ MS spectrometer fitted with an electro spray ionization interface. The ESI-MS was operated in both positive and negative detection mode. Calibration of the mass analyzer was performed by infusion $\left(10 \mu 1 \mathrm{~min}^{-1}\right)$ of a commercial mixture of polypropylene glycol (PPG) which was supplied by AB SCIEX using a $1 \mathrm{ml}$ Hamilton syringe and monitored eight mass-to-charge ratios $(\mathrm{m} / \mathrm{z})$ in the $59-1800$ mass range. The ESI source conditions were: ion spray voltage, $5500 \mathrm{~V}$; nebulizer gas (GS1), 50 psi; curtain gas, 25 psi; turbo gas (GS2), 50 psi; collision gas (CAD), 7 psi and ion source temperature $470^{\circ} \mathrm{C}$.

\section{Results}

\section{HPTLC method optimization and validation}

To optimize the HPTLC parameters, several mobile phase compositions were tried. Satisfactory development of Luliconazole was obtained with mobile phase consisting of toluene- methanolethyl acetate $(6.0: 2.5: 0.5 \mathrm{v} / \mathrm{v} / \mathrm{v})$ as mobile phase, It was observed that Luliconazole showed maximum absorption at $300 \mathrm{~nm}$ (Figure 3), hence the densitometric scanning was performed at $300.00 \mathrm{~nm}$ for all the measurements. The mobile phase enabled good resolution, a sharp and symmetrical peak of $R_{f} 0.62 \pm 0.05$ (Figure 4) from a compact and non diffuse band. Linearity and range: The linear regression data revealed a good linear relationship over the concentration range of $100-600 \mathrm{ng} /$ band with correlation coefficient $\left(\mathrm{r}^{2}=0.983\right)$, shown in (Figure 5). The results are showed in Table 1.

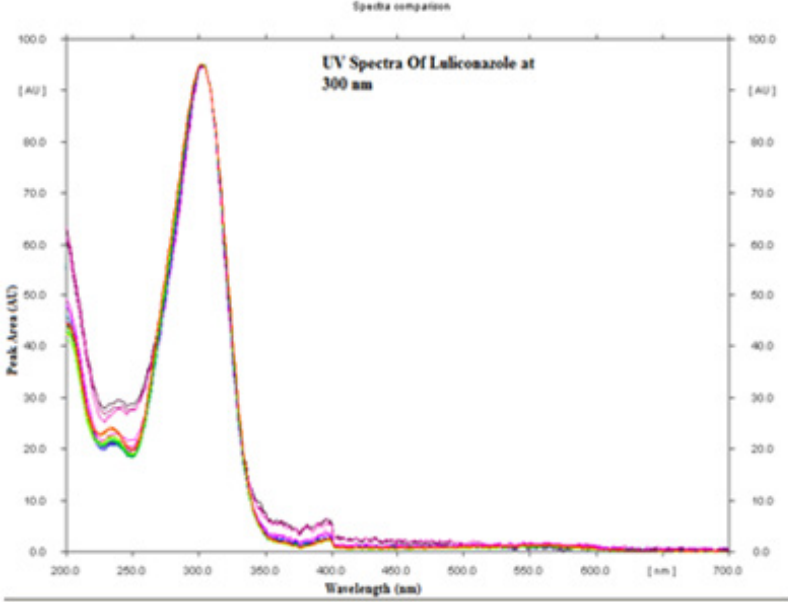

Figure 3 Spectra of Luliconazole.

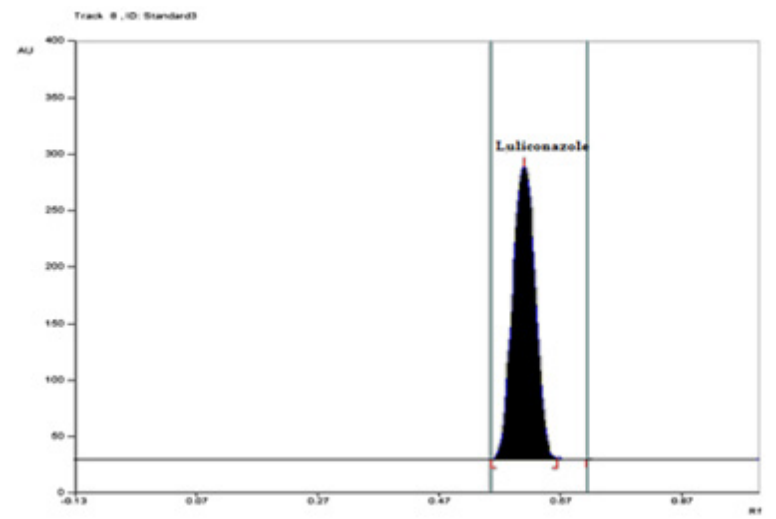

Figure 4 Representative chromatogram for Luliconazole (300ng/spot), $R_{f} 0.62 \pm 0.05$.

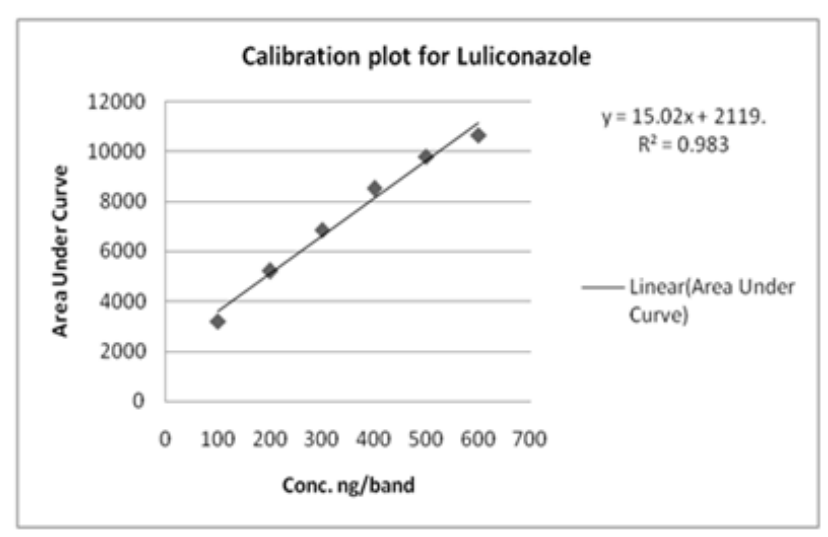

Figure 5 Representative linearity of Luliconazole.

Table I Calibration Parameters of Luliconazole for HPTLC

\begin{tabular}{ll}
\hline Parameter & Luliconazole \\
\hline Linearity range & $100-600 \mathrm{ng} /$ band \\
Slope $(\mathrm{m})$ & 15.02 \\
Intercept $(\mathrm{c})$ & 2119 \\
LOD $(\mathrm{ng} /$ band) & $27 \mathrm{ng} /$ band \\
LOQ $(\mathrm{ng} /$ band) & $83 \mathrm{ng} /$ band \\
Intra-day (Mean of $\mathrm{n}=9) \% R S D$ & $0.94 \%$ \\
Inter-day (Mean of $\mathrm{n}=18) \% \mathrm{RSD}$ & $2.16 \%$ \\
\hline
\end{tabular}

Abbreviations: LOD: Limit of Detection; LOQ- Limit of Quantitation; RSD: Relative Standard Deviation

Precision: The proposed method was found to be precise as indicated by $\%$ RSD, when the results of intra-day and inter-day were subjected to one-way ANOVA and F values were calculated at each QC level, the $F$ values were found to be less than the tabulated $F$ values. This indicated that there was no significant difference between intra-and inter-day variability at $\mathrm{p}<0.01$ as shown in Table $2 \& 3$, suggesting good intermediate precision.

Table 2 Results of method precision Intraday for Luliconazole $(n=6)$

\begin{tabular}{llll}
\hline Conc.(ng/Band) & $\mathbf{1 0 0 ( n g / B a n d )}$ & $\mathbf{3 0 0}(\mathbf{n g} /$ Band) & $\mathbf{6 0 0}(\mathbf{n g} /$ Band $)$ \\
\hline Intraday I & 3222 & 6782 & 10781 \\
Intraday 2 & 3187 & 6877 & 10567 \\
Intraday 3 & 3208 & 6948 & 10598 \\
Mean \pm S.D. & $3206 \pm 17.59$ & $6869 \pm 83.70$ & $10649 \pm 115.65$ \\
ANOVA(F-value) & 0.73 & 1.2 & 5.72 \\
\%RSD & 0.54 & 1.2 & 1.08 \\
Mean \%RSD & & 0.94 &
\end{tabular}

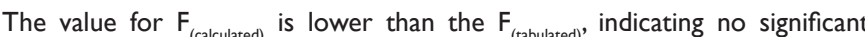
difference between the intraday variability at $p<0.01$. Abbreviations: $S D$ : Standard Deviation; RSD: Relative Standard Deviation; ANOVA: Analysis of Variance

Table 3 Results of method precision Inter-day for Luliconazole $(n=6)$

\begin{tabular}{llll} 
Conc.(ng/Band) & $\mathbf{I 0 0}(\mathbf{n g} /$ Band) & $\mathbf{3 0 0}(\mathbf{n g} /$ Band) & $\mathbf{6 0 0}(\mathbf{n g} /$ Band) \\
\hline Interday I & 3008 & 6330 & 10010 \\
Interday 2 & 3060 & 6632 & $1026 \mathrm{I}$ \\
Interday 3 & $304 \mathrm{I}$ & 6540 & 10087 \\
Mean \pm S.D. & $3036 \pm 43.50$ & $6501 \pm 203.56$ & $10119 \pm 195.08$ \\
ANOVA (F-Value) & 2.65 & 6.18 & 3.3 \\
\%RSD & 1.43 & 3.13 & 1.92 \\
Mean \%RSD & 2.16 & & \\
\hline
\end{tabular}

The value for $F_{\text {(calculated) }}$ is lower than the $F_{\text {(tabulated) }}$, indicating no significant difference between the inter-day variability at $\mathrm{P}<0.0 \mathrm{I}$. Abbreviations: SDStandard Deviation, RSD-Relative Standard Deviation, ANOVA-Analysis of Variance 
Accuracy: The proposed method when used for the estimation of Luliconazole from pharmaceutical dosage form after spiking with the standard, afforded recovery of $99.56-100.51 \%$ at different levels was found. The results obtained by the proposed method were statistically compared with those of the literature method. ${ }^{15}$ By applying the Student's t-test for accuracy, the calculated $t$ - values $(t=1.68)$ was found to be less than the tabulated value, $\mathrm{t}=4.303$ at $95 \%$ confidence level, for two degrees of freedom suggesting that the proposed method and the literature method ${ }^{15}$ do not differ significantly with respect to accuracy. The results of analysis are depicted in Table 4.

Limit of detection (LOD) and limit of quantification (LOQ): The limit of detection and limit of quantification was $27 \mathrm{ng} /$ band and $83 \mathrm{ng}$ /band respectively.

Robustness: Robustness was checked by making a slight deliberate change in the experimental parameters i.e. change in Mobile phase composition, Change in saturation time, change in scan speed, change in wavelength and chromatogram was run. Robustness of the method was checked at middle concentration of $300 \mathrm{ng} / \mathrm{spot}$. The method was found to be robust since the peak area values were not significantly affected. The results of analysis are depicted in Table 5 .

Specificity: The method was found to be specific since no interferences spots were seen when carried out in presence of additives. The spot for Luliconazole in the sample was confirmed by comparing $R_{f}$ values of the spot with that of the standard. As shown in Figure $6 \& 7$. As active constituent is soluble in methanol where as additives are insoluble in methanol.

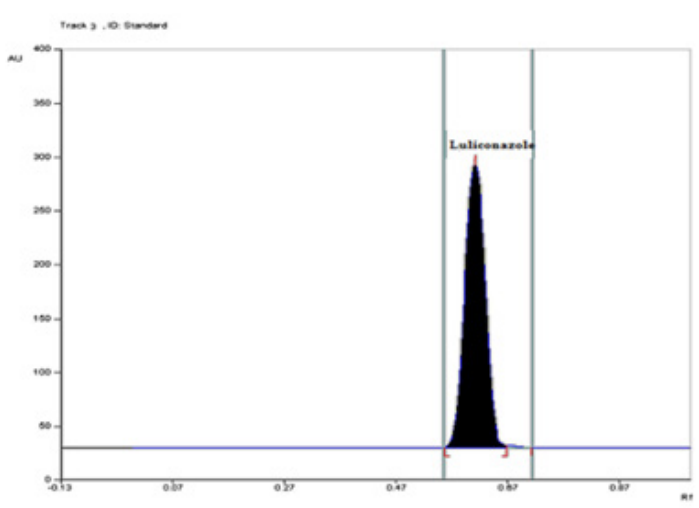

Figure 6 Representative chromatogram for standard Luliconazole (300ng/ spot), Rf $0.61 \pm 0.05$.

Recovery in biological fluid: The recovery of Luliiconazole in biological fluid for HPTLC at the concentration 300ng/spot in triplicates were found to be $100.36 \%$ as shown in Table 6 . There is no interference of the biological fluid in the quantitation of Luliconazole as shown in Figure 8. There were no changes in $R_{f}$ of Luliconazole, hence the method is selective.

Mass spectrometry: Mass spectrometric analysis of the samples resulted in a spectrum showing molecular ion peak at $355.1 \mathrm{~m} / \mathrm{z}$. Mass spectrometric characterization resulted in direct confirmation in identifying the drug as shown in (Figure 2).

Table 4 Results of accuracy of Luliconazole and Statistical comparison with Literature method

\begin{tabular}{llllll}
$\begin{array}{l}\text { Recovery } \\
\text { Level }\end{array}$ & $\begin{array}{l}\text { Initial Amount } \\
\text { (ng/Band) }\end{array}$ & $\begin{array}{l}\text { Conc. of Standard Drug } \\
\text { added (ng/Band) }\end{array}$ & $\begin{array}{l}\text { Mean*\% } \\
\text { Recovery } \pm \text { S.D. }\end{array}$ & \%RSD & t-Value \\
\hline $80 \%$ & 200 & 160 & $99.56 \pm 0.317$ & 0.32 & 1.68 \\
$100 \%$ & 200 & 200 & $100.51 \pm 1.010$ & 1 & 0.09 \\
$120 \%$ & 200 & 240 & $99.67 \pm 0.0945$ & 0.47 \\
\end{tabular}

(no. of determinations $=3$ per conc.) for HPTLC, *Average of three determinants. There was no significance difference between the methods using Student's- $t$ test, where $t$ tabulated $=4.303$ at $95 \%$ confidence level. Abbreviations: SD: Standard Deviation; RSD: Relative Standard Deviation;ANOVA:Analysis of Variance

Table 5 Results for robustness study (no. of determinations=3) of Luliconazole, conc. 300ng/band.

\begin{tabular}{|c|c|c|c|}
\hline Sr. No. & Parameters Checked & $\%$ RSD of Area & Mean \%RSD of Area \\
\hline \multirow[t]{3}{*}{ I } & Change in Saturation time & & $1.31 \%$ \\
\hline & a)At $10 \min .(n=3)$ & $0.99 \%$ & \\
\hline & b)At $15 \min .(n=3)$ & $1.63 \%$ & \\
\hline \multirow[t]{3}{*}{2} & Change in Mobile Phase Composition & & $2.21 \%$ \\
\hline & E.A. $0.4 \mathrm{ml}(\mathrm{n}=3)$ & $3.11 \%$ & \\
\hline & E.A. $0.6 \mathrm{ml}(\mathrm{n}=3)$ & $1.31 \%$ & \\
\hline \multirow[t]{4}{*}{3} & Change in wavelength $(300 \mathrm{~nm} \pm 2)$ & & \\
\hline & At $298 \mathrm{~nm}(\mathrm{n}=3)$ & $0.91 \%$ & $0.95 \%$ \\
\hline & At $300 \mathrm{~nm}(\mathrm{n}=3)$ & $1.07 \%$ & \\
\hline & At $302 \mathrm{~nm}(\mathrm{n}=3)$ & $0.89 \%$ & \\
\hline \multirow[t]{6}{*}{4} & Change in slit width & & $1.09 \%$ \\
\hline & $6 \times 0.20 \mathrm{~mm}$, micro & $1.08 \%$ & \\
\hline & $6 \times 0.45 \mathrm{~mm}$, micro & $1.05 \%$ & \\
\hline & $6 \times 0.40 \mathrm{~mm}$, micro & $1.05 \%$ & \\
\hline & $6 \times 0.10 \mathrm{~mm}$, micro & $1.06 \%$ & \\
\hline & $6 \times 0.30 \mathrm{~mm}$,micro(used for analysis) & $1.24 \%$ & \\
\hline \multirow[t]{4}{*}{5} & Change in scan speed & & $1.12 \%$ \\
\hline & $10 \mathrm{~mm} / \mathrm{sec}$ & $1.08 \%$ & \\
\hline & $40 \mathrm{~mm} / \mathrm{sec}$ & $1.05 \%$ & \\
\hline & $20 \mathrm{~mm} / \mathrm{sec}$.(used for analysis) & $1.24 \%$ & \\
\hline
\end{tabular}

Abbreviations: RSD: Relative Standard Deviation 
Table 6 Result of recovery of Luliconazole (no. of determinations=3 per conc.) in Biological fluid.

\begin{tabular}{lllll}
\hline Sr.No. & Conc.(ng/band) & \% Recovery (Mean of $n=3)$ & SD & \%RSD \\
\hline $\mathrm{I}$ & 300 & 100.36 & 0.69 & 0.69 \\
\hline
\end{tabular}

Abbreviations: SD: Standard Deviation; RSD: Relative Standard Deviation

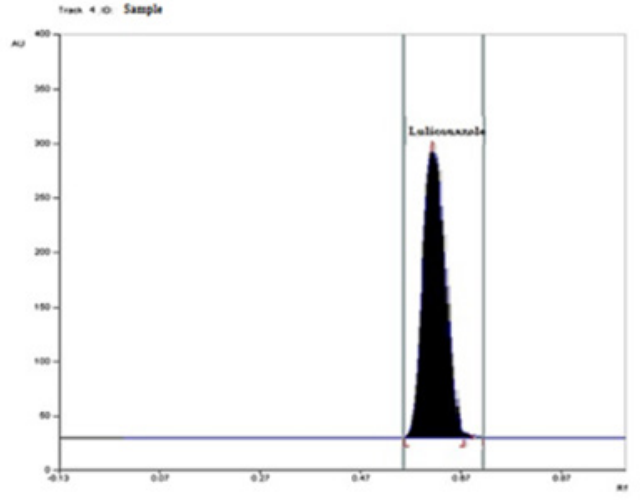

Figure 7 Representative chromatogram for marketed formulation of Luliconazole (300ng/spot), Rf 0.60 0.05 .

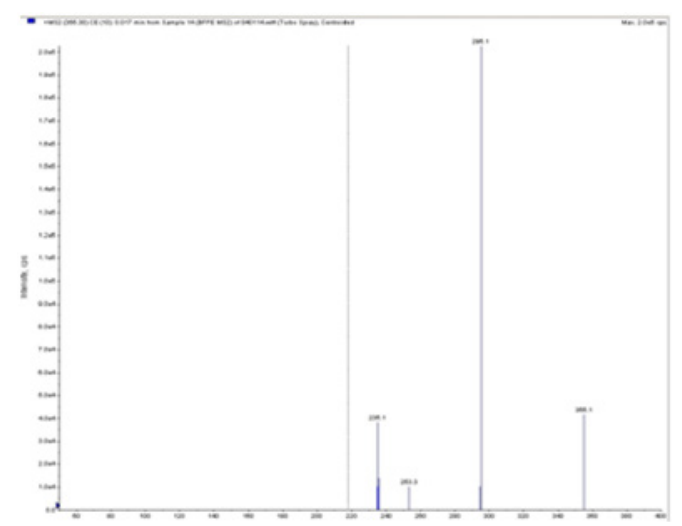

Figure 8 Mass spectrum for luliconazole.

\section{Discussion}

A HPTLC/densitometric method has been developed successfully for the determination of Luliconazole as bulk drug, in marketed formulation and in biological fluid. The estimation of drug was performed on pre-coated silica gel 60 F254 TLC aluminium plates ( $0.25 \mathrm{~mm}$ thick) using toluene- methanol- ethyl acetate $(6.0: 2.5: 0.5)$ as a mobile phase. The densitometric quantification for the drug was carried out at $300 \mathrm{~nm}$. The Rf value for Luliconazole was found to be 0.62 .The proposed method has been validated for various parameters like linearity, accuracy, precision, sensitivity as per ICH guidelines. The calibration curve was obtained by plotting peak area against concentration. It showed linearity in the concentration range of 100 $600 \mathrm{ng} / \mathrm{band}$.

Malasia et al., ${ }^{15}$ have reported Method Development and Validation of RP HPLC Method for Assay and related Substances of Luliconazole in Topical Dosage form using Inertsil ODS 3V (4.6x $150 \mathrm{~mm}, 5 \mu \mathrm{m})$ by RPHPLC method. The mobile phase used was ammonium acetate buffer and ACN (60:40). In another study, Desai and Maheshwari ${ }^{16}$ have reported U.V. Spectrophotometric method for estimation of Luliconazole in marketed formulation. The LOD and LOQ, $0.38 \mu \mathrm{g} / \mathrm{ml}$ and $1.06 \mu \mathrm{g} / \mathrm{ml}$ respectively, whereas the HPTLC method showed LOD and LOQ values as $27 \mathrm{ng} / \mathrm{band}$ and $83 \mathrm{ng} /$ band respectively. The proposed HPTLC method is thus found to be more sensitive and economical in comparison to the earlier reported methods. ${ }^{15,16}$

The mean recovery for Luliconazole in marketed formulation and biological fluid was found to be $99.91 \%$ and $100.36 \%$ respectively. As the $R_{f}$ values of Luliconazole in bulk, marketed formulation and biological fluid was the same, we could safely conclude that there was no interference of excipients and matrix components. The intraday and inter-day precision results expressed as \%RSD were found to be less than $5 \%$. There was no significant difference in $\%$ RSD values. $F$ values calculated by one way ANOVA, is less than tabulated at $p<$ 0.01 . The Student's t-test was performed for accuracy. The calculated $\mathrm{t}$ - value $\mathrm{t}=1.68$ was found to be less than the tabulated value, $(\mathrm{t}=4.303)$ at $95 \%$ confidence level, suggesting that the proposed method and the literature method ${ }^{15}$ do not differ significantly with respect to accuracy.

The robustness of an analytical procedure is a measure of its capacity to remain unaffected by small, but deliberate variations in method parameters, and provides an indication of its reliability during normal usage. In robustness study, the RSD percentage was less than $5 \%$. We also propose the current method is convenient for the routine estimation of Luliconazole as a bulk drug in marketed formulation and from biological fluid. Till date no HPTLC method has been reported for quantitative estimation of LCZ except stability indicating method, RP-HPLC and UV spectrophotometric method, so we could develop HPTLC method for analysis of Luliconazole in marketed formulation and biological fluid.

\section{Conclusion}

The reported HPTLC method has been developed for the identification and quantitation of Luliconazole. It surpasses the earlier methods on the basis of low cost per analysis, faster with satisfactory precision. Method was successfully validated as per ICH guidelines .The validation data, one way ANOVA (F-test) and Student's t test proves that method is sensitive, specific, precise, accurate and statistically significant. It can be conveniently employed for routine quality control analysis of Luliconazole as bulk drug and in marketed formulation without any interference from excipients also in biological fluid. We can further explore this method for various analytical reasons.

\section{Acknowledgements}

None.

\section{Conflicts of interest}

Author declares there are no conflicts of interest.

\section{Funding}

None.

\section{References}

1. Havlickova B, Czaika VA, Friedrich M. Epidemiological trends in skin mycoses world wide. Mycoses. 2008;51(4):-15.

2. Borman AM, Campbell CK, Fraser M, et al. Analysis of dermatophyte species isolated in the British Isles between 1980 and 2005 and review of worldwide dermatophyte trends over the last three decades. Med Mycol. 2007;45(2):131-141. 
3. Sei Y. 2011 Epidemiological survey of dermatohmcoses in Japan. Med Mycol J. 2015;56(4):129-135.

4. Nishimoto K. An epidemiological survey of dermatomycoses in Japan, 2002. Nihon Ishinkin Gakkai Zasshi. 2006;47(2):103-111.

5. Drakensjö IT, Chryssanthou E. Epidemiology of dermatophyte infections in Stockholm, Sweden: a retrospective study from 2005-2009. Med Mycol . 2011;49(5):484-488.

6. Foster KW, Ghannoum MA, Elewski BE. Epidemiological surveillance of cutaneous fungal infection in United States from 1999 to 2002. J Am Acad Dermatol . 2004;50(5):748-752.

7. Gupta AK, Cooper EA. Update in antifungal therapy of dermatophytosis. Mycopathologia. 2008;166(5-6):353-367.

8. Saunte DM, Hasselby JP, Brillowska-Dabrowska A, et al. Experimental guinea pig model of dermatophy- tosis: a simple and useful tool for the evaluation of new diagnostics and antifungals. Med Mycol. 2008;46(4):303-313.

9. Koga $\mathrm{H}$, Nanjoh Y, Makimura $\mathrm{K}$, et al. In vitro antifungal activities of luliconazole, a new topical imidazole. Med Mycol. 2009;47(6):640647.

10. Koga $\mathrm{H}$, Tsuji $\mathrm{Y}$, Inoue $\mathrm{K}$, et al. In vitro antifungal activity of luliconazole against clinical isolates from patients with dermatomycoses. $J$ Infect Chemother. 2006;12(3):163-165.
11. Koga H. Evaluation of NND-502 regarding affinity to stratum -adsorption to and release from keratin Data on file. 2012;113.

12. Uchida K, Nishiyama Y, Yamaguchi H. In vitro antifungal activity of luliconazole (NND-502), a novel imidazole antifungal agent. $J$ Infect Chemother. 2004;10(4):216-219.

13. Sonawane S, Gide P. Application of experimental design for the optimization of forced degradation and development of a validated stability- indicating LC method for luliconazole in bulk and cream formulation. Arabian Journal of Chemistry. 2006;9(2):S1428-S1434.

14. Leahy MK, Gesier L, Wang Morton K, et al. Development of an LCMS/MS method for the determination of the luliconazole in human toenails. Topica Pharmaceuticals, India. 2013.

15. Malasiya Aditi, Goyal Aditi. Method Development and Validation of RP HPLC Method for Assay and related Substances of Luliconazole in Topical Dosage form. IJPCA. 2017;4(2):46-50.

16. Desai NJ, Maheshwari DG. UV Spectrophotometric Method for the Estimation of Luliconazole in Marketed Formulation (Lotion). IJPSR .2014;5(2):48-54.

17. ICH.Validation of Analytical Procedures: Text and Methodology. International Council for Harmonisation, USA. 2005. p.1-13. 